\title{
Applying the social determinants of health lens to the situation of young key populations in Zambia: what can it tell us about what we could do?
}

\author{
Russell Armstrong ${ }^{1}$, Joseph Zulu ${ }^{2}$ \\ ${ }^{1}$ Health Economics and HIV/AIDS Research Division, University of KwaZulu-Natal, Durban, South Africa, ${ }^{2}$ School of Public Health, Health Promotion \\ and Education Department, University of Zambia, Lusaka, Zambia \\ Keywords: global health \\ https://doi.org/10.29392/joghr.3.e2019008
}

\section{Journal of Global Health Reports}

Vol. 3, 2019

\section{Background}

According to census data, Zambia has a predominantly young population with $65 \%$ under the age of 25 years. Improving the sexual and reproductive health of young people aged 15-24 years has become a crossing-cutting priority for sustainable development for the country. Certain sub-groups within this population, namely young gay men and other men-having-sex-with-men; young sex workers; young transgender people; and young prisoners - collectively termed key populations - may have poorer sexual and reproductive health than their general population peers. The application of the social determinants of health framework offers a way to understand these inequities in order to more effectively address them.

\section{Methods}

Data and other information to support this analysis were collected using key informant interviews and desk review. Interviews were conducted with 30 individuals deemed to be knowledgeable about the situation of young key populations in Zambia. Peer-reviewed literature on these groups is very limited. As a result, non-peer-reviewed sources were also used.

\section{Results}

According to the limited information that is available, young key populations do indeed have significantly poorer sexual reproductive health, particularly elevated rates of HIV and other sexually transmitted infections. This may arise due to a range of determinants linked to a general context of marginalisation and disadvantage, as well as the more specific pathways related to the effects of punitive laws and policies; negative socio-cultural beliefs and practices; a high degree of social exclusion; and limited or no access to relevant and acceptable health services. While, in this last regard, tailored HIV-focussed programming is beginning to expand for some groups, it is not yet addressing these broader forces of risk and vulnerability.

\section{Conclusion}

The growing attention to young key populations in Zambia is both appropriate and necessary. However, more research is urgently needed to guide this emphasis. The social determinants of health can provide a highly relevant organising framework for this work. Should further investigation confirm some of the conclusions of this analysis, more will be needed to achieve health equity for young key populations than tailored services alone. Enabling, inclusive, and protective legal, policy and programmatic approaches will be equally critical.

Census data for Zambia for 2010, the most recent available, showed that $56 \%$ of the population was under the age of 19 years and $65 \%$ under the age of 25 . One third (35\%) was between 10 and 24 years. ${ }^{1}$ This demographic makeup reflects continental trends. ${ }^{2}$ It is not surprising, then, that Zambia's Seventh National Development Plan 2017-2021 identifies the health and well-being of its youthful population as a cross-cutting priority. ${ }^{3}$ The plan seeks to address this through, amongst other things, creating a favourable environment "that ensures [all] citizens claim their rights to education, health, development, and live free from violence and discrimination," and "where no Zambian is margin- 
alised in benefitting from development (emphasis added)." For Zambia, the pathway towards greater prosperity for its young people is premised, then, on fulfilling the rights of citizenship to equal shares of primary social goods, such as education and health care, by, amongst other things, preventing or eliminating discrimination, violence and marginalisation in all their forms.

Where young people currently find themselves on this pathway is still at some distance from what the plan outlines. Data on core socio-economic indicators, as well as recent analyses of development prospects, illustrate this. ${ }^{4}$, ${ }^{5}$ For example, $65 \%$ of Zambia's population live below the nationally defined poverty threshold of US $\$ 1.90$ per day, a proportion that is largely made up of young people. ${ }^{4}$ While country data show that $80 \%$ of $20-24$-year-olds are in the labour force, most are engaged in "vulnerable employment", which is primarily made up of self-employment in subsistence agriculture in rural areas or unpaid domestic work. ${ }^{4,5}$ Within this same age group, only as many as $14 \%$ have completed primary school and 13\% secondary school, although most, overall, have some level of schooling. ${ }^{4}$

Recently adopted policies and strategies highlight the health dimensions of these structural challenges, particularly the Adolescent Health Strategy 2017-2021, the National Health Strategic Plan 2017-2021, and the National HIV/AIDS Strategic Framework 2017-2021. ${ }^{6-8}$ A common strand running through them is the importance of achieving sexual and reproductive health (SRH) for older adolescents and young people aged 15-24 years. The rationale for this is the growing range of poor SRH outcomes for this group that are linked to a host of issues, including elevated levels of risk and vulnerability to HIV and other sexually transmitted infections (STIs); early entry into child-bearing; early and forced marriages; sexual and gender-based violence; sexual exploitation and abuse; low levels of knowledge regarding sexuality and sexual health; and, low uptake of and retention in available SRH services, including HIV treatment. ${ }^{6,8-10}$

Moving forward to address this situation for the country requires that those groups of adolescents and young people whose SRH outcomes are the poorest be identified, and that the root causes of this be investigated. Other countries across the Southern African region are beginning to do this work and, as a result, there is growing attention to young people from key populations which are generally identified as sex workers of all genders (male, female and transgender); people who use drugs; people in prisons; men who have sex with men (MSM); and lesbian, gay, bisexual and transgender (LGBT) individuals. ${ }^{11}$ For Zambia, there is also an emerging focus on these groups, although mostly in the context of the HIV response and, for the moment, only obliquely as part of other efforts to improve SRH more generally. $6,8,12$ While this is nevertheless encouraging, such progress is occurring in a context that is challenging and contradictory and where the many aspects of the complex, lived realities of young key populations that influence their SRH are neither fully recognised nor addressed.

This discussion probes this situation using the social determinants of health framework. ${ }^{13}$ It finds that, although the evidence is currently very limited, there is enough to suggest that young key populations in Zambia have sig- nificantly poorer SRH and that this arises as a result of a range of factors. However, none of these issues can be understood to any degree of analytical precision unless additional comprehensive and inclusive research is carried out. The analysis concludes that, until this work is done, a significant 'blind spot' will remain for health and development planning for young people in the country, and progress for sustainable development through the full realisation of this "demographic dividend" may be compromised. ${ }^{2}$

\section{THE SOCIAL DETERMINANTS OF HEALTH INEQUITIES}

Applying the social determinants of health lens to the situation of young key populations in Zambia has an important value. It is highly useful for illuminating how differences in SRH arise, particularly for population groups who experience multiple forms of marginalisation or exclusion. ${ }^{13}$ It leads us towards considering these differences as inequities, or lack of equal shares in health and well-being, and to gauge the extent to which they arise from unfair, avoidable, or remediable factors-or, to put it another way, from things that could be changed through corrective measures in the domains of law, policy or programming.

However, to arrive at this endpoint, the social determinants framework asks us to examine in depth a number of different elements starting with the social position of individuals or groups that, in itself, has an overall determining influence on levels of better or poorer SRH linked to degrees of social advantage or disadvantage. It also asks us to go even deeper to consider how additional factors play a role in individual or group level SRH, including material circumstances (effects of poverty on access to shelter or food, for example); behavioural factors (high risk sexual behaviour, or alcohol or other drug use); psychosocial factors (traumatising effects of verbal or physical violence); social cohesion (impact of isolation from family or from exclusion from social, cultural or religious activities); and, access to and interactions with the health system (experiences of stigma and discrimination from health care workers and their effects on whether or not someone uses health services at all).

The use of the social determinants lens, then, can generate a comprehensive and highly nuanced view of what drives SRH outcomes for young key populations, one that goes beyond any single factor such as whether or not individuals use condoms or clean needles. It also allows us to investigate not only differences in health between these groups and their non-key-populations peers, but also differences between and within the groups themselves and why this may be so. Finally, the results of the analysis may point towards a programme of action centred around social justice that combines health interventions with other elements, such as changes in law or policy that protect against discrimination, reduce poverty and guarantee access to health services.

\section{METHODOLOGY}

Data and other information to support this analysis was collected using key informant interviews and desk review. Using a purposive sampling approach, individuals deemed to be knowledgeable about the situation of young key popu- 
lations in the country were approached for interviews. The National HIV/AIDS/STI/TB Council (NAC) in Zambia provided an initial list of respondents and assisted the researchers to secure interviews. Topics addressing key populations remain controversial in Zambia and, consequently, the support of NAC was essential to encourage individuals to participate in the study. Following informed consent procedures, interviews were conducted using a semi-structured interview guide. Amongst the 30 individuals interviewed were representatives from governmental and non-governmental entities, international organisations, technical partners, and from key-population-led groups themselves. This last category of respondents included representatives from national organisations working with young gay, lesbian and bisexual individuals; young transgender men and women; young male and female sex workers; and young drug users. All respondents were 18 years or older.

For the desk review, documents were collected using internet-based searches and via the key informant interviews. Peer-reviewed literature on SRH for young key populations in Zambia is very limited. As a result, non-peer-reviewed sources, such as programme documents and research reports, have also been used to inform the analysis. Interview notes and documents were analysed using thematic analysis aligned to the components of the social determinants of health framework. The results were validated by the National Key Populations Technical Working Group during a session organised by NAC. The results have also informed the development of a research programme which has been approved by the University of Zambia and the University of KwaZulu Natal.

\section{RESULTS}

\section{YOUNG KEY POPULATIONS IN ZAMBIA AND THEIR SOCIAL POSITION}

Who are young key populations and how are they situated relative to other young people in the country? Some quantitative data on socio-economic status and other social characteristics of young sexual minorities give, at least, an indicative picture. For example, there are some data in a 2013 study on issues of HIV prevention for "sexual minority groups," defined by the researchers as gay men and other MSM, lesbians and other women-having-sex-with-women (WSW), and transgender persons. ${ }^{14}$ In the study, $82 \%$ of the 450 respondents were aged $18-25$ years. With regard to socio-economic characteristics, $72 \%$ of study participants had at least some primary or secondary education; $49.5 \%$ of males and $36 \%$ of females were currently employed in some form of remunerated work (including being self-employed); and $28 \%$ of males and $41 \%$ of females were students. As a comparator across the general population of young people in Zambia, also in 2013, 90\% of 20-to-24-year-old males and females had at least some primary or secondary education while $65 \%$ of males and $40 \%$ of females where currently employed. ${ }^{15}$ Are there substantive differences here between the population groups? These data cannot say but the comparisons suggest how a further analysis could proceed in order to more clearly situate young MSM or WSW within the wider population of young people in Zambia and, moreover, to more clearly know what influence socio-economic characteristics can have, if any, on differences in SRH outcomes.

There are no similar, quantitative data on other young key populations. There are, however, a range of qualitative sources for all groups that also speak to issues of socio-economic disadvantage. There are many anecdotal accounts of individuals living in poverty as a result of being denied educational opportunities (passed over for educational support within families, for example); of having to leave school because of discrimination and violence; or, of being turned away from employment. ${ }^{16-20}$ However, whether or not there is more absolute disadvantage for young key populations, given the broader context of poverty and inequality for all young people in Zambia, as noted previously, has yet to be determined. What is important, though, is the extent to which individuals may be pushed to such margins as a result of actions or contexts that are unjust or unfair and, on this topic, more information is indeed available.

\section{THE DRIVERS OF MARGINALISATION AND EXCLUSION}

In all of the accounts of young key populations in Zambia, criminal statutes and prevailing socio-cultural beliefs and practices are said to drive marginalisation and exclusion. On the legal side, punitive criminal laws, most of which date from the pre-Independence period, cast a dark shadow over the lives of young people with same-sex desires or attachments, for example, even if these laws are only selectively enforced. ${ }^{16-19}$ The litany of such effects is long and includes: highly publicised police actions meant to expose perceived criminality and immoral conduct; arrests, detention, and physical and sexual abuse of individuals, in violation of Constitutional protections against such abuses; a general culture of impunity within communities for acts of verbal, physical and sexual harassment and abuse, sometimes merely on the basis of appearances that are deemed to be outside of established (and frequently violently enforced) cultural norms regarding gender; and, bribery and extortion, using the threat of criminal exposure, including between gay or bisexual men themselves. ${ }^{16,17,19,20}$

Punitive drug laws have a similar effect and, in addition to criminalising specific forms of drug use, also prevent the introduction of harm reduction interventions which are considered under these laws to constitute condoning or promoting illegal drug use. ${ }^{18}$ 'Sodomy' is a major offence in prisons which, while limiting the range of HIV or other SRH interventions that can be implemented for this population, also imposes a heavy institutional silence on the full spectrum of male-male sexual behaviour that occurs in these settings, including sexual coercion and rape. ${ }^{18,21,22}$

On the socio-cultural side, the Constitutional assertion of the primacy of Christianity is reflective of a socio-cultural ethos that remains intolerant to the diversity of social identities and sexual practices that characterise young gay or transgender people, for example. ${ }^{17,18}$ It continues to be stated by some (if erroneously) that the country's ethnic traditions are also strongly Christian-based and that homosexuality and other forms of diversity, such as being transgender, are un-Zambian and threaten the integrity and continuity of traditional identity. ${ }^{19,20,23}$ Sex workers face similar forms of cultural and social ostracisation, largely 
through local beliefs that what they do is not only 'sinful' but also in opposition to what is considered a proper cultural and social role for a Zambian woman. ${ }^{24}$ Amongst other things, these factors affect self-esteem and agency, and negatively affect health seeking behaviour for fear of exposure and judgement, not only in health services, but in family and community environments as well. ${ }^{24,25}$

\section{THE SEXUAL AND REPRODUCTIVE HEALTH OF YOUNG KEY POPULATIONS}

How might the degree of disadvantage, marginalisation or exclusion faced by young key populations be related to their $\mathrm{SRH}$, both on their own and in comparison with their nonkey-population peers? Such data for young key populations are few but what is available suggests much poorer SRH outcomes. The 2013 study on sexual minorities, noted above, found the following HIV prevalence rates for young MSM and WSW, as shown in Figure $1 .{ }^{14}$

As the data indicate, there were substantial differences in HIV prevalence between younger versus older age groups for both males and females. The large jump in prevalence between the age groups is disturbing and is something that the study did not explore. By comparison, population-wide HIV prevalence for similar age groups in 2013 was much lower where it was $4.1 \%$ and $7.3 \%$ for adolescent (15-19 years) and young (20-24 years) males, respectively, and $4.8 \%$ and $11.2 \%$ for adolescent and young females. ${ }^{15}$ While there was a similar jump in prevalence between age groups for all females (a more than 100\% increase in both cases), it was more pronounced for MSM than for other males.

In 2014, the burden of HIV amongst young sex workers was substantial. ${ }^{24}$ Figure 2 shows the distribution of HIV prevalence across the five data collection sites for the study. It also shows rates for other sexually transmitted infections.

It is disturbing to note that HIV prevalence reached as high as $53.6 \%$, and prevalence for syphilis $32.8 \%$. Comparable rates in 2014 for all adolescent girls (15-19 years) and young women (20-24 years) were $4.8 \%$ and $11.2 \%$ for HIV, as already noted, and 4,9\% and $9.8 \%$ for syphilis. As for transgender youth and young people in prison, there are no quantitative data on SRH indicators. In their personal accounts, however, transgender youth describe poor SRH, including untreated HIV infection or STIs, and other reproductive health concerns. ${ }^{16,20}$ For young prisoners, while there are no data on their SRH, there is some information on their SRH risks which is discussed in the next section.

\section{DETERMINANTS OF POOR SEXUAL AND REPRODUCTIVE HEALTH}

What can account for what appear to be substantial differences in SRH outcomes, at least between young LGBT persons or sex workers and other adolescents or young people? There is some information about a number of factors or determinants and how they may increase vulnerability to poorer SRH. This includes how they overlap or intersect to increase the magnitude of their negative effects. Amongst younger MSM, for example, exchanging sex for money or other material benefits from older partners is said to be a main feature of their sexual culture. ${ }^{14,17}$ Alleviating poverty

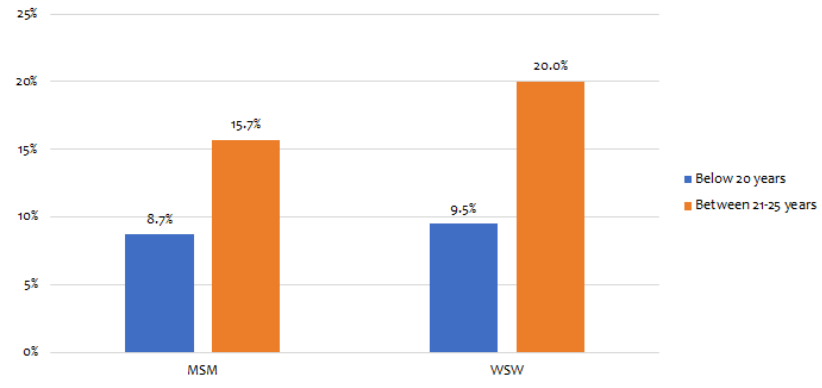

\section{Figure 1}

HIV prevalence among young MSM and WSW in Zambia ( $\mathrm{n}=367$ ) (Kiefer et al. 2013). MSM - men-having-sex-with men; WSW - women-having-sex-withwomen.

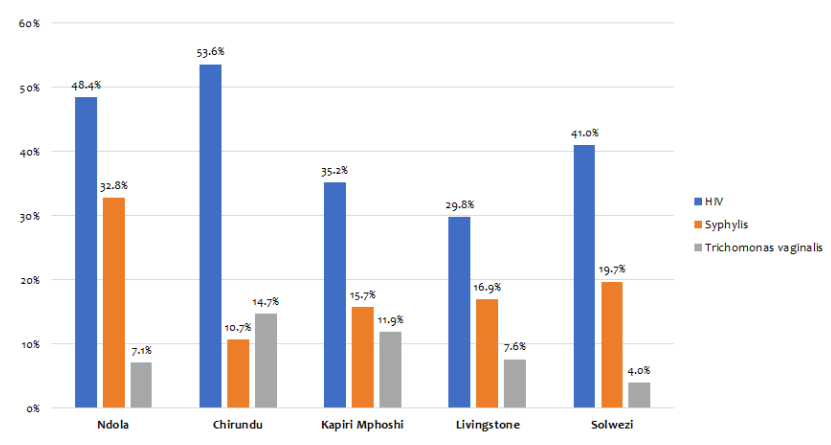

\section{Figure 2}

Prevalence of HIV, syphilis and Trichomonas vaginalis among young female sex workers (age 14-24) in five hot spot towns in Zambia, by site $(\mathrm{n}=491)$ (Kasongo et al. 2015).

is one reason for this practice. ${ }^{17}$ For young sex workers, a similar analysis can be made. Women, particularly young women, are generally poorer than their male peers in Zambia. ${ }^{15}$ While for some sex workers these constitute "push factors," for younger sex workers the influence of poverty and inequality as a pathway to sex work is greater. ${ }^{24,25}$ Such inequalities shape the power dynamics of transactions in sex work and affect whether or not condoms are used, for example. ${ }^{24}$ Socio-cultural norms attached to women and sexuality also shape the dynamics of private relationships for sex workers where, for example, condom use with intimate partners is even lower due to partner reluctance or instance to avoid them ${ }^{24,26}$ Finally, such inequalities also affect risk for physical and sexual violence and abuse, from clients, intimate partners, men in communities and the police, amongst others, particularly where young women involved in sex work are considered to have little to no moral or social value $18,24,26$

One final example from prisons is given highlighting the aspect of material conditions, particularly access to food, as a determinant of SRH risk. Although against the law in Zambia, older adolescents are incarcerated with adults in some facilities. ${ }^{21,27}$ In this context, they are at risk of sexual exploitation, amongst other abuses, particularly given prison conditions, which include overcrowding, gang-related activities and chronic under-nourishment. ${ }^{21,28}$ One 
respondent in the study by Topp et al (2016) has described what these risks can entail 27 :

\begin{abstract}
"You can imagine the young ones. They will be admiring food. They don't get full [from prison rations]. So they will ask for some food [from another inmate]. He will be given [...] and when they try to sodomise him he can't refuse because that person is the one giving him food. So he will just give him his buttocks.”
\end{abstract}

\section{THE ROLE OF THE HEALTH SYSTEM}

Within the social determinants of health framework, the health system plays an important mediating role between elevated risks for poor SRH outcomes and such outcomes themselves. ${ }^{13}$ At an overall level for young key population groups, such as MSM, sex workers or drug users, although it may be difficult to control or overcome their circumstances of SRH risk, the provision of pre-exposure prophylaxis, MSM or sex worker "friendly" clinics, targeted outreach programmes, or harm reduction interventions, can still reduce the potential for negative SRH outcomes, such as HIV infection. ${ }^{29}$

As a general feature of the situation in Zambia, the role of the health system to mediate against poor SRH for young key populations is very limited. This arises from the context surrounding these groups and how it affects, on the one hand, what health care providers think and do when a young MSM or sex worker seeks their assistance, and, on the other, what these same young people anticipate and frequently avoid in terms of breaches of privacy, or exposure to ridicule or other abuse that demeans them. ${ }^{16,17}$ As a result, health care workers do not provide needed care, although in too many instances this is done in highly inappropriate and abusive ways. ${ }^{17,30,31}$ The personal impacts of ridicule and abuse are far-reaching in these accounts and are indeed magnified by the inherent nature of the vulnerability of all patients in health care encounters. The injury to self-esteem from public humiliation and abuse in a health facility, and the consequences of breaches of privacy to parents or family members, have deep ramifications for some and result in subsequent avoidance of the health system altogether. ${ }^{17,30}$

\section{DISCUSSION}

As already noted, an important feature of the social determinants of health lens is its ability to clarify the complex aetiology of inequities in health outcomes, especially for disadvantaged or marginalised groups. It positions such inequities as more than just technical issues, lack of appropriate understanding or diagnosis of health needs, for example, or lack of access to or availability of needed services. Rather, they become issues of social justice in that they constitute lack of equal shares of health or well-being in comparison to others, a situation that arises because of unfair or unjust factors. As the analysis has attempted to show, such is the case for young key populations in Zambia, at least to the extent that some form of evidence is available.

Fortunately, things are on the move for some young key populations in Zambia, with new programmes responding to their SRH needs, mostly made possible through invest- ments by the Global Fund to Fight AIDS, TB and Malaria and the United States President's Emergency Plan for AIDS Relief. ${ }^{19,31,32}$ While there has for some time been a growing and increasingly well-structured LGBT community in Zambia, which has stayed away from public notice for evident reasons, this is now beginning to change. ${ }^{19}$ Some gaps still remain, however. Programmes are expanding faster than the pace of substantive law or policy change. ${ }^{17,18}$ All are externally funded and are operating mostly as stand-alone programmes outside of the public health sector. Some groups are not yet included in these efforts, such as drug users, young transgender men or women, or lesbians and bisexual women. Furthermore, adolescents younger than 18 years from key populations, in Zambia and elsewhere in the region, are excluded in multiple ways from SRH programmes targeting their older peers, including those that are key-population-led themselves. ${ }^{33,34}$ Service providers fear falling afoul of criminal laws and key-population-led entities fear being seen to be "recruiting" adolescents into homosexuality or sex work. One can only speculate about the impact of this exclusion when one considers that, according to available data, $50 \%$ of sex workers began selling sex before the age of 19 years, and 38\% of MSM had their first same-sex sexual experience before the age of 16 years. ${ }^{14,24}$

\section{LIMITATIONS}

The analysis is subject to some important limitations. Peerreviewed data on the SRH of young key population groups is almost non-existent in Zambia and, as a result, there is a greater reliance on non-peer-reviewed sources the quality of which could not be fully verified by the research team. As the article makes clear, open discussion about key populations in Zambia is a relatively recent development and remains controversial and divisive meaning that the pool of potential key informants was limited. Some individuals with important perspectives on the issues addressed by the analysis declined to participate for fear of negative consequences to them or to their positions as a result. Despite these challenges, however, sufficient information was available to make a reasonable case for the importance of using the social determinants lens as a means towards a more comprehensive approach, whether in research, policy or programming, for improving the SRH of young key populations in Zambia.

\section{CONCLUSION}

The growing attention to the SRH of young key populations in Zambia is both appropriate and necessary. However, for this work to unfold on firmer ground a deeper analysis is needed, one that is derived from a more comprehensive body of evidence. The social determinants of health can provide an organising framework for this work in terms of pointing out what the priorities for further research and analysis should be and, subsequently, what actions should be taken once the extent of SRH inequities for young key populations is more clearly known. These research priorities could include: 
Describing young key populations in Zambia: There are no comprehensive descriptions of these groups in all of their diversity for the country. There is a growing continental literature to show that identities are layered and more continuous than the current key populations categories would suggest. There is a need to evolve a more nuanced way of framing disadvantage or marginalisation for these young people. A 'ground up' analysis for Zambia is a critical first step.

Describing SRH inequities: As presented in the analysis, there are some data for HIV and other STIs. However, a much broader spectrum of data is needed that is specific to young key population groupings however these are subsequently defined for Zambia.

Identifying the social determinants of the inequities: The analysis has sketched what some of these determinants may be but more in depth investigation is needed.

Describing the contribution of these inequities to broader SRH trends for young people: The analysis should probe, for example, the extent to which the current gap in HIV treatment for young people is made up of young people from key population groups without access to such services, or of those that are highly reluctant to use them. ${ }^{9}$

If some of the tentative findings of this analysis are confirmed through such additional research more will be needed to achieve SRH equity than tailored services alone, as well designed and as well intentioned as current efforts may be. Enabling, comprehensive and protective legal, policy and programmatic approaches will be equally critical.

Why should these additional efforts matter? As an illustration of this imperative, currently, in Zambia, complications arising from advanced HIV infection is the leading cause of death for all adolescents and young people aged 10-24 years. 9,35 To the extent that young key populations continue to bear a high burden of HIV, and have least access to HIV treatment for the kinds of unjust and remediable reasons that this analysis has explored, the disease burden remains high overall for the country and the lives of young people, the erstwhile engine of sustainable development for Zambia, continue to be lost. Addressing this gap in HIV programming is not the only reason to act to improve the SRH for young key populations-but it is surely one of the more urgent.

\section{ACKNOWLEDGEMENTS}

The study was approved by the Biomedical Research Ethics Committees of the University of KwaZulu-Natal and the University of Zambia and the Zambia National Health Research Authority. The views expressed in this article are those of the authors and do not represent the official position of the University of KwaZulu-Natal or the University of Zambia. The study is part of a larger research collaborative involving similar work in Angola, Madagascar, Mozambique and Zimbabwe. Other members of the research team, led by Nana K. Poku and including Carolien Aantjes, Tamaryn Crankshaw, Jane Freedman, Timothy Quinlan and Michael Strauss, have contributed to the elaboration of the social determinants of health approach to guide further research and programme development aimed towards improving the sexual and reproductive health of young key populations across southern Africa. The authors are grateful for the ability to draw on this collective work for this article.

\section{FUNDING}

This article was prepared with the support of a project grant from the Ministry of Foreign Affairs of The Netherlands through its Leave No one Behind Initiative.

\section{COMPETING INTERESTS}

The authors completed the Unified Competing Interest form at http://www.icmje.org/coi_disclosure.pdf (available upon request from the corresponding author), and declare no conflicts of interest.

\section{CORRESPONDENCE TO:}

Russell Armstrong, MScMed

Health Economics and HIV/AIDS Research Division

University of KwaZulu-Natal

Private Bag X54001

Durban 4000

South Africa

ArmstrongR@ukzn.ac.za 


\section{REFERENCES}

1. Central Statistical Office. Census of Population and Housing. National Analytical Report. Central Statistical Office; 2010. Accessed September 18, 2018. https://w ww.zamstats.gov.zm/phocadownload/2010 Census/20 10\%20Census\%20of\%20Population\%20National\%20A nalytical\%20Report.pdf

2. African Union. AU Roadmap on Harnessing the Demographic Dividend Through Investments in Youth. In Response to AU Assembly Decision (Assembly/AU/ Dec.601 (XXVI) on the 2017 Theme of the Year. African Union; 2017. Accessed September 18, 2018. http://wca ro.unfpa.org/sites/default/files/pub-pdf/AU\%20201 7\%20DD\%20ROADMAP\%20Final\%20-\%20EN.pdf

3. Ministry of National Development Planning. Seventh National Development Plan 2017-2021. Ministry of National Development Planning; 2017. Accessed September 18, 2018. http://www.mndp.go v.zm/download/7NDP.pdf

4. Central Statistical Office. Selected Socio-Economic Indicators Report 2015. Revised Edition. Central Statistical Office; 2016. Accessed September 18, 2018. https://www.zamstats.gov.zm/phocadownload/Disse mination/2015\%20Selected\%20Socio-economic\%20In dicators\%20Final.pdf

5. United Nations Development Programme. Zambia Human Development Report 2016: Industrialisation and Human Development. Poverty Reduction through Wealth and Employment Creation. UNDP; 2017. Accessed September 18, 2018. http://hdr.undp.org/sites/defaul t/files/zambia_human development_report_2016.pdf

6. Ministry of Health. Adolescent Health Strategy 2017-2021. Ministry of Health; 2017.

7. Ministry of Health. National Health Strategic Plan 2017-2021. Ministry of Health; 2017. Accessed September 18, 2018. http://www.moh.gov.zm/docs/Za mbiaNHSP.pdf

8. National HIV/AIDS/STI/TB Council. Zambia's National HIV and AIDS Strategic Framework (NASF) 2017-2021. National HIV/AIDS/STI/TB Council; 2017. Accessed September 18, 2018. https://www.nac.org.z $\mathrm{m} /$ content/national-aids-strategic-framework-nasf-2 $\underline{017-2021}$

9. Ministry of Health. Zambia Population-Based HIV Impact Assessment (ZAMPHIA) 2016. First Report. Ministry of Health; 2016. Accessed September 18, 2018. https://phia.icap.columbia.edu/wp-content/upl oads/2017/11/FINAL-ZAMPHIA-First-Report_11.30.1 7 CK.pdf
10. United Nations Children's Fund. A Report Card of Adolescents in Zambia. UNICEF; 2012. Accessed September 18, 2018. https://www.unicef.org/zambia/ A Report Card Of Adolescents In Zambia.pdf

11. Southern African Development Community (SADC). SADC Regional Strategy for HIV and AIDS Prevention, Treatment and Care and Sexual and Reproductive Health and Rights among Key Populations 2017-2020. SADC; 2017. Accessed September 18, 2018. https://www.sadc.int/files/2715/3060/7629/SAD C-regional-strategy-hiv-srhr-key-pops FINAL.pdf

12. Ministry of Health. Adolescent HIV Guidelines. Ministry of Health; 2016.

13. World Health Organisation. A Conceptual Framework for the Social Determinants of Health. WHO; 2010. Accessed September 18, 2018. http://ww w.who.int/sdhconference/resources/Conceptualframe workforactiononSDH_eng.pdf

14. Kiefer L, Witola H, Hansende D, Handema R, Siantombo N. Report of the Study on HIV Prevention for Sexual Minority Groups in Zambia. Panos Institute for Southern Africa; 2013. Accessed September 18, 2018. http://www.panos.org.zm/wp-content/uploads/2017/ 04/Panos-Study-on-Sexual-Minorities-in-Zambia-Re port.pdf

15. Central Statistical Office. Zambia Demographic and Health Survey 2013-2014. Central Statistical Office; 2015. Accessed September 18, 2018. https://w ww.dhsprogram.com/pubs/pdf/fr304/fr304.pdf

16. Engender Rights Centre for Justice. Friends of Rainka, Generation Alive, TransBantu Zambia, The Lotus Identity, Women's Alliance for Equality, Coalition of African Lesbians, Sexual Rights Initiative. Joint Submission to the Universal Periodic Review for Zambia. 28th Session. Engender Rights Centre for Justice; 2017.

17. Hachoonda H. Final Report of the Desk Review and Stakeholder Consultations on Human Rights Status of People of Diverse Sexual Orientation and Gender Identity (SOGI) in Zambia. UNDP and Office of the United Nations High Commissioner for Human Rights; 2017.

18. National Alliance of State and Territorial AIDS Directors (NASTAD) Zambia. Legal, Policy and SocioCultural Barriers to HIV-Related Prevention, Treatment, Care, and Support for Key Populations in Zambia. NASTAD Zambia; 2015. Accessed September 18, 2018. https://www.nastad.org/sites/default/files/resources/ docs/Zambia_Law_Review.pdf 
19. Phiri L. Canaries in the Coal Mines: An Analysis of Spaces for LGBTI Activism in Zambia. The Other Foundation; 2017. Accessed September 18, 2018. htt p://theotherfoundation.org/wp-content/uploads/201 7/02/Canaries_Zambia.pdf

20. TransBantu Zambia. Environment and Challenges of Transgender and Intersex Zambians: The Community. TransBantu Zambia; 2014.

21. Todrys KW, Amon JJ. Human rights and health among juvenile prisoners in Zambia. Int J Prison Health. 2011;7:10-17.

22. Telisinghe L, Charalambous S, Topp SM, et al. HIV and tuberculosis in prisons in sub-Saharan Africa. Lancet. 2016;388(10050):1215-1227. doi:10.1016/s014 $\underline{0-6736(16) 30578-5}$

23. van Klinken A. Queer Love in a "Christian Nation": Zambian Gay Men Negotiating Sexual and Religious Identities. J Am Acad Relig.

2015;83(4):947-964. doi:10.1093/jaarel/lfv073

24. Butts S, Parmley L, Alcaide M, et al. Let us fight and support one another: adolescent girls and young women on contributors and solutions for HIV risk in Zambia. Int J Womens Health. 2017;9:727-737. doi:1 $\underline{0.2147 / i j w h . s 142232}$

25. Kasongo W, Temb M, Mwakazanga D, Kamanga J, Mwape F, Chelu L. Integrated Biological and Behavioural Surveillance Survey (IBBSS) among Female Sex Workers and Behavioural Surveillance Survey (BSS) among Male Long-Distance Truck Drivers in Five Corridors of Hope Project District Sites in Zambia. National HIV/AIDS/STI/TB Council; 2015. Accessed September 18, 2018. https://www.nac.org.zm/sites/de fault/files/publications/IBBS\%202015\%20Final\%20Re port\%204\%20March\%202016.pdf

26. Scorgie F, Chersich MF, Ntaganira I, Gerbase A, Lule F, Lo YR. Socio-Demographic Characteristics and Behavioral Risk Factors of Female Sex Workers in Sub-Saharan Africa: A Systematic Review. AIDS Behav. 2012;16(4):920-933. doi:10.1007/s10461-011-9 $\underline{985-\mathrm{Z}}$

27. Topp SM, Moonga CN, Luo N, et al. Exploring the drivers of health and healthcare access in Zambian prisons: a health systems approach. Health Policy Plan. 2016;31(9):1250-1261. doi:10.1093/heapol/czw0 $\underline{59}$
28. Kumwenda M, Nzala S, Zulu JM. Health care needs assessment among adolescents in correctional institutions in Zambia: an ethical analysis. BMC Health Serv Res. 2017;17(1). doi:10.1186/s12913-01 7-2532-5

29. Delany-Moretlwe S, Cowan FM, Busza J, BoltonMoore C, Kelley K, Fairlie L. Providing comprehensive health services for young key populations: needs, barriers and gaps. J Int AIDS Soc. 2015;18(2). doi:10.7 $\underline{448 / \mathrm{IAS} .18 .2 .19833}$

30. Southern African Litigation Centre. Accountability and Redress for Discrimination in Healthcare in Botswana, Malawi and Zambia. Southern African Litigation Centre; 2016. Accessed September 18, 2018. https://www.southernafricalitigationcentre.org/ wp-content/uploads/2017/08/Report-Accountability-a nd-Redress-for-Discrimination-in-Healthcare.pdf

31. Zulu J, Ngwenya Z, Silukena M, Phiri Z, Chiseni A. Integrating friendly sexual and reproductive health services for young female sex workers into the health system at district level in Zambia: perspectives of stakeholders. Health Res Policy Syst. 2015;2:1-8.

32. United States President's Emergency Plan for AIDS Relief (PEPFAR). PEPFAR Zambia Country Operational Plan (COP) 2018 Strategic Directions Summary. Department of State; 2017. Accessed September 18, 2018. https://www.pepfar.gov/documents/organizatio $\underline{\mathrm{n} / 272026 . p d f}$

33. Müller A, Spencer S, Meer T, Daskilewicz K. The no-go zone: a qualitative study of access to sexual and reproductive health services for sexual and gender minority adolescents in Southern Africa. Reprod Health. 2018;15(1). doi:10.1186/s12978-018-0 462-2

34. Cornell M, Dovel K. Reaching Key Adolescent Populations. Curr Opin HIV AIDS. 2018;13:274-280. $\underline{\mathrm{d}}$ oi:10.1097/COH.0000000000000457

35. Patton GC, Sawyer SM, Santelli JS, et al. Our future: a Lancet commission on adolescent health and wellbeing. Lancet. 2016;387(10036):2423-2478. ㅁ oi:10.1016/s0140-6736(16)00579-1 